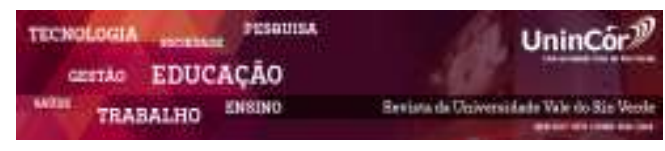

Revista da Universidade Vale do Rio Verde ISSN: 1517-0276 / EISSN: 2236-5362 Vol. 16 | n. 2 | Ano 2018

Bruno Gadelha Xavier Doutorando em Filosofia pela Universidade Federal do Rio de Janeiro (UFRJ) brunogadelhaxavier@hotmail.com

\section{A ANGÚSTIA VEM DE MEßKIRCH? DELIMITAÇÕES SOBRE O CONCEITO DE ANGÚSTIA NA FILOSOFIA DE MARTIN HEIDEGGER}

\begin{abstract}
RESUMO
O presente artigo tem como objetivo debater o conceito de angústia a partir de um recorte temático baseado na filosofia de Martin Heidegger, caracterizando-a como um elemento que se difere do temor (Furcht). Compreende-se enquanto Angst uma figura firmada como uma disposição afetiva (Befindlichkeit) que reúne condições que impulsionam a abertura do Dasein. Parte-se do princípio de que o temor se apresenta como uma formulação nuclear na existência, possuindo três elementos: wofür, fürchten, e worum. Neste sentido, outro sentimento de apresentado pelo $\mathrm{Da}$ sein se coloca frente a cotidianidade, que, desde já, é confrontada pela decaída que acompanha a angústia. A partir destas problemáticas busca-se uma contribuição conceitual para a temática em análise a partir de uma metodologia pautada no close reading das obras selecionadas e dos comentadores utilizados.
\end{abstract}

Palavras-chave: Angústia; Temor; Dasein.

\begin{abstract}
This article aims to discuss the concept of anguish from a thematic focus based on the philosophy of Martin Heidegger, characterizing it as an element that differs from fear (Furcht). We understand Angst as a figure signed as an affective disposition (Befindlichkeit) that meets conditions that drives the opening of Dasein. It starts from the principle that fear is presented as a nuclear formulation in existence, having, therefore, three elements: wofür, fürchten and worum. In this context, another sense presented by Dasein stands in front of everydayness, which already is confronted by the fallen that accompanying anxiety. Taking these problematics, this article searches for a conceptual contribution to the subject in question from a guided methodology with the use of close readings of the selected works and commentators.
\end{abstract}

Keywords: Anguish; Fear; Dasein.

Recebido em: 06/03/2018 - Aprovado em: 30/08/2018 - Disponibilizado em: 15/12/2018 


\section{INTRODUÇÂO}

Pode encontrar dubiedade a afirmação de que todo o grande pensador possui essencialmente uma ideia marcante, central. A dificuldade em pensar tal afirmação em sede dos principais nomes da filosofia ocidental é uma tentativa - indiscutivelmente ingrata - de elencar essa dita única "grande ideia". Entretanto, como afirma Frede (1993, p.42), pode-se afirmar que há uma grande questão que norteia o pensamento: tal proposição se enquadra no viés de Martin Heidegger, e o questionamento que o perseguiu durante toda sua vida, qual seja, em uma manobra ontológica mais ampla possível indagar acerca do ser.

Ora, conforme afirma Gaos (1986, p.19), a Filosofia pode ser vista como um corpo de disciplinas, nas quais restariam inseridas a metafísica, a lógica, a ética, dentre outros. A ontologia, seja tomada como uma disciplina independente, ou seja tomada por uma parte da metafísica, pode considerar-se como a disciplina filosófica principal ou fundamental, uma vez tratar, justamente, acerca do ser.

Ao certo, Martin Heidegger é um dos mais influentes filósofos do século $\mathrm{XX}$, tendo seu trabalho alvo de apropriação epistemológica por parte de estudantes dos mais diversos campos do saber, como a Filosofia, Psicologia, História, Sociologia, Antropologia, Literatura, Religião, Ciência Política, dentre outros. Entretanto, em que pese sua ampla importância, se engana quem acredita ser sua obra de fácil compreensão, o que, afirma-se, não se deu sem razão aparente segundo Dreyfus e Wrathall
(2005, p.1), uma vez que o filósofo buscava romper com uma tradição filosófica.

Seu intento proporcionou a criação de neologismos que resultavam em termos linguísticos desprovidos do peso de uma tradição filosófica específica, um método que provocou em seus leitores um desafio único: através de suas palavras o desafio do fazer refletir almejando uma nova forma de filosofar (DREYFUS, WRATHALL, 2005, p.1).

Posta a introdução supramencionada, vale dizer que o presente artigo almeja a discussão acerca da angústia em "Ser e Tempo". Dito isto, a impessoalidade que caracteriza a cotidianidade oculta a contingência dotada de radicalidade e finitude, que é a existência humana, o ser-no-mundo. Neste sentido, as figuras da consciência, morte, culpa a angústia são dotadas de capacidade única de desocultar a situação acima delineada a fim de conduzir o Dasein a si mesmo, ao seu modo de ser originário. Vale tecer, então, o estudo em torno do supradelineado.

\section{SOBRE O CONCEITO DE ANGÚSTIA NO PENSAMENTO DE MARTIN HEIDEGGER: NOTAS INICIAIS?}

Decaído de suas possibilidades próprias, o Dasein pode ser fruto de uma postura que assuma a existência impessoal no cotidiano guiando-se pelas possibilidades entregues por este - resultando em uma vivência a partir das possibilidades vislumbradas na abertura do mundo (SHEEHAN, 2005, p.206). O Dasein acaba sendo refém da lógica do absorver 
cotidiano, sendo superficial, assim, se entretém e se diverte como "a gente" se diverte, do mesmo modo se vê e se julga sobre arte e literatura como "a gente" faz, se afasta das "grandes multidões" como "a gente" deveria, uma visão mimética irritante (HEIDEGGER, 1998, p.151).

Neste sentido, a deficiência decorrente do influxo cotidiano acerca da compreensão e do cuidado encobre o modo de ser do Dasein, demandando algo que autorize o encobrir, concluindo em modos compreensivos no qual o ser-aí possua um acesso a si mesmo de maneira privilegiada, a fim de superar os desafios da impessoalidade do dia-a-dia.

Resta, portanto, afirmar a proposição heideggeriana da angústia (Angst), firmada como uma disposição afetiva (Befindlichkeit) apta a reunir condições propiciando a abertura do Dasein para si mesmo. O demonstrar de suas determinações existenciais confirma uma fundamentação propriamente fenomênica do captar da totalidade originária do ser do Dasein (HEIDEGGER, 1998, p.205).

Assim, a vertente totalizante que almeja definir a essência do ser humano se dá no conceito de angústia. Somente esta oferece base hermenêutica e fenomenológica para compreensão da totalidade originária, não se reduzindo a mero fenômeno psicológico ou ôntico, sendo ontológico.

Insta mencionar que, de maneira semelhante ao intento de Søren Kierkegaard, a visualização da angústia ganha o significado em Heidegger de um prisma existencial humano em sua essência. Entretanto, o primeiro mantém sua postura ao afirmar que a angústia acaba por revelar o ser finito, o nada da existência humana frente a infinitude divina, algo que Heidegger não compactuou, refletindo acerca da angústia como um fenômeno existencial da humana finitude.

A partir do parágrafo 40 de "Ser e Tempo", o filósofo traça como um ponto genético a ideia de decaída. A apropriação no impessoal e no visto mundo com que se direcionam preocupações cotidianas expõe uma fuga do próprio Dasein, esta fuga de si é algo verificável no diaa-dia, uma vez as preocupações delineadas pelo impessoal que o encilham de sua condição de ser-no-mundo (HEIDEGGER, 1998, p.207).

Neste momento, é de bom alvitre destacar a função da angústia caracterizada como - de acordo com o supramencionado - uma disposição afetiva fundamental. Neste prisma, se difere do temor/medo (Furcht), sendo adjetivada como uma figura a qual colocada a frente de remissões, faz com que a totalidade dos entes seja destituída de importância, fazendo com que o mundo adquira uma completa insignificância (HEIDEGGER, 1998, p.208).

A fim de continuar a dissertação sobre a angústia no pensamento de Martin Heidegger, passa-se ao fator de distinção entre esta e o temor/medo, ponto seguinte o qual será trabalhado a fim de colocar um novo fator para a continuidade elucidativa acerca da temática.

\section{COMO A ANGÚSTIA NÃO DEVE SER TOMADA COMO TEMOR/MEDO}

Em que pese o temor/medo seja encarado como um existente fundamental frente o qual o homem pode se encontrar no mundo (vide $\$ 30$ ), sendo assim um estágio mais leve da angústia, 
esta não deve ser confundida com o primeiro. $\mathrm{O}$ medo deve ser visto como uma disposição anímica, poderosa no sentido de nos desviar ou afastar de algo que se teme, manifestando a totalidade do mundo em sua vertente estranha e assombrosa. Representa uma angústia caída no "mundo", sendo imprópria e oculta enquanto tal para si mesma (HEIDEGGER, 1998, p.212).

Vale trazer a discussão o fato de que a força de revelação do mundo no temor/medo é demasiadamente superior do que qualquer outra via de acesso ao mundo, como a felicidade, transitória e muito menos incisiva e marcante. Deve-se lembrar que o ser-aí situa-se lançado no mundo (geworfen) em meio a uma plúrima de estados anímicos, nos quais resulta passível de se desviar do mundo enquanto tal, uma vez o existir do peso da própria existência (WERLE, 2003, p.105-107).

O medo/temor se apresenta como um elemento central na existência por manifestar o mundo no formular da fuga do ser-aí de si mesmo, de modo que o homem teme por algo que se pode determinar uma vez que ele mesmo será afetado. O medo se volta para quem teme, sendo ele o maior interessado, dirigindo-se ao íntimo. Desta feita, o parágrafo $\$ 30$ de "Ser e Tempo" trará informações deveras relevantes. Heidegger relatará três elementos essenciais que compõem o medo/temor (WERLE, 2003, p.105107).

O primeiro elemento da equação heideggeriana acerca do medo/temor é, justamente, o elemento wofür, o "diante de que" se teme algo. Assume-se o caráter ameaçador, pois, tem-se algo que ameaça - seja uma copresença ou ausência dos outros ou um ente qualquer. Adiciona-se a tal existencial elemento o fürchten, ou seja, o temer, que possui o potencial de abrir o mundo para o humano (WERLE, 2003, p.105-107).

Como terceiro elemento observa-se o worum, o porquê que se teme, algo que se refere ao estar-aí. Sendo um fenômeno eminentemente privado, o medo/temor pode ser em relação ao outro, quando se assume o medo deste no momento em este afirma não ter medo de nada. Ademais, o temor/medo pode ser tripartido em o que se faz assustador, o horror, ou a decepção (WERLE, 2003, p.105-107).

Calha destacar que a cisão conceitual entre angústia e temor/medo remete a amplitude da primeira em relação à segunda - vide seu texto sobre "Que é metafísica" (HEIDEGGER, 1989, p.39). Ora, o medo/temor direciona-se a um determinado ente presente na existência humana, entretanto, ao se observar da angústia, corrobora-se um substrato no qual o objeto ao qual esta se dirige é indeterminado. No caso da angústia não se sabe, ao certo, diante de que se angustia, sendo ela uma resultante de cunho quase sintomático que se apresenta no seio das ocupações cotidianas, quando se sente um superveniente tédio (FERREIRA, 2002, p.3).

Um sentimento de fatura em torno dos entes que nos circundam aparece, não encontrando elemento de apoio algum para a situação de moficiar. Ao contrário, denuncia-se o caráter contínuo do contato com os entes e as coisas mundanas como uma forma de se ocupar (besorgen), ao invés de se preocupar (fürsorgen) em sair da indiferença. 


\section{A ANGÚSTIA COMO RESULTADO DO PRÓPRIO ATO DE EXISTIR}

Em sua obra denominada "Heidegger e a essência do ser", Michel Haar (1990, p.82) afirma que a angústia constrói uma ponte comunicacional entre o nada e o ser. Em sede deste existencial, os termos que fazem sentido em torno do ente se revertem em uma totalidade de remissões. O Dasein cai, quase que sublimemente, em um vazio de sentido.

Que se reforce o fato de que na angústia os entes caem no nada, e no nada transluz o ser como o nada dos entes, conforme relatou Ernildo Stein (2002, p.69). O ente intramundano se manifesta tão insignificante que segue impondo-se o mundo em sua mundanidade (HEIDEGGER, 1998, p.209). Na angústia abre-se o mundo enquanto mundo (mundanidade), possibilitando a observância da imperceptibilidade cotidiana do próprio mundo. Deste modo, o "ante quê" da angústia se faz na mundanidade, e, com isso, o próprio ser-no-mundo exsurge, com o descobrimento do mundo (SEIBT, 2009, p.184).

Se solidifica a estirpe cognitiva do presente com a afirmação de que o Dasein não consegue compreender-se a partir da medianidade da cotidianidade, do impessoal, uma resultante direta da angústia pulsante que retira a possibilidade do humano de compreensão a partir dos entes do mundo (SEIBT, 2009, p.184), singularizando-o e afetando seus movimentos de maneira a isolá-lo e colocá-lo diante do ser poder-ser (HAAR, 1990, p.82). Reforçando, mais uma vez, a lição de Stein (2000, p.59), quando diz que o Dasein não possui fundo, é abissal, possui a sua fundamentação na pura possibilidade.

Vale dizer, a partir deste prisma, que o Dasein enquanto ente que compreende se projeta em possibilidades. $\mathrm{O}$ elemento angústia o abre para o seu ser-possível, partindo unicamente de si mesmo revelando seu ser livre com intuito de liberdade de escolher-se e sacar-se a si mesmo nas mãos, descobrindo-se livre para uma autêntica existência (HEIDEGGER， 1998, p.210).

A sensação de ambientalidade e tranquilidade que o Dasein se coloca frente a cotidianidade é confrontada pela decaída que acompanha a angústia, introduzindo total estranheza e afastando a familiaridade daquele com outros entes e consigo mesmo. Ela demonstra a ausência de necessidades, e que o almejar contínuo e mimético da segurança no dia-a-dia é, simplesmente, um radical escapismo da situação de estar lançado no mundo (geworfen) e entregue a sua particularidade (FERREIRA, 2002, p.4).

Insta citar, então, a genialidade do autor no momento em que este reconhece que o fenômeno mais originário é o Dasein em uma postura de estranhamento, não se sentindo acolhido (FERREIRA, 2002, p.4). Apesar de tal fato, a angústia ainda se mantém em pouca proporção no ser, o Dasein poucas vezes se angustia por estar em constante fuga de si mesmo, um movimento autofágico e cíclico frente o reinado do cotidiano, encobrindo seu ser-no-mundo (SEIBT, 2009, p.185), com mais medo do que angústia.

A raridade da angústia demonstra a força da impessoalidade frente o Dasein, habituando 
um ocultamento constante. Somente através da angústia a abertura privilegiada poderá ocorrer. A singularização (Vereinzelung) propiciada por ela afasta a decaída revelando possibilidade de ser propriamente ou impropriamente, demonstrando as possibilidades fundamentais do Dasein em si mesmas.

\section{APORTES CONCLUSIVOS}

Com o fim do século $\mathrm{XX}$, restou claro em termos do campo filosófico que Martin Heidegger deve ser considerado um dos grandes filósofos da humanidade. Seus escritos obtiveram influência inigualável não apenas na Europa, bem como nas localidades as quais o inglês é língua fluente, e também na Ásia. "Ser e Tempo" se mantém não somente como um dos grandes escritos filosóficos, mas também como a obra mais conhecida e de maior influência do autor - em que pese seus densos termos e estilo peculiar - trazendo uma nova e fresca forma de se pensar os enigmas filosóficos, transformando em transparente um ente - o qual questiona em seu ser (GUIGNON, 1993, p.12).

O presente trabalho procura concluir em que pese saber da infelicidade do emprego do termo conclusão para trabalhos acadêmicos que detém como base uma obra heideggeriana, uma contraditio in terminis - a sua tentativa de elucidação acerca do tema indicando a temática da angústia em Heidegger.

O que se considera é, justamente, a angústia como porto abertura e demonstração ao Dasein do ter-que-ser, posto ele estar lançado no mundo (geworfen). O ser-aí é responsável pelo ser seu, e, sendo, está em jogo o seu próprio ser
(HEIDEGGER, 1998, p.213). A angústia demonstra o abandono do Dasein a si mesmo e a libertação, para possibilidade da impropriedade e da propriedade, com uma escolha de si mesmo pelo ponto de partida de si mesmo, se antecipando a si mesmo, se precedendo pela compreensão. Acrescenta-se o fator o qual ele sempre se coloca determinado com as preocupações mundanas, não decaído de forma indiferente na existência, mantendo encoberto uma estranheza resultante da adesão à impessoalidade (SEIBT, 2009, p.196).

O Dasein é sempre um ser de possiblidades, no momento em que antecipa-se a si mesmo ele subsiste na hipótese de ser liberto para as possibilidades existentivas, comportandose involuntariamente com relação a suas possibilidades, sendo impróprio como de fato sucesso de modo imediato e regular (HEIDEGGER, 1998, p.215).

Assim, a entrega ao impessoal é ocasionada pela postura do Dasein em se relacionar de modo involuntário com suas múltiplas possibilidades. Mantem-se em observância ser próprio ser, recebendo possibilidades a partir do descoberto mundo, resultantes da interpretação coletiva pública publicidade do mundo -, caso o qual as possibilidades de opção se encontram restringidas de maneira antecipada à vertente aberta e adjetivada no dia-a-dia (SEIBT, 2009, p.196).

Por fim, corrobora-se a postura de Martin Heidegger no vislumbrar das possibilidades do ser-próprio, posto que é implausível o extirpar do Dasein de sua situação de facticidade, de ser-no-mundo, relacionando-se 
com os entes intramundanos e consigo mesmo. Tal possibilidade busca sua elaboração a partir dos existenciais da angústia - bem como, por exemplo, do ser-para-morte, ademais, do chamado da consciência à resolução - que propicia o Dasein se abrir para ser ser-próprio, fazendo com que o cotidiano perca seu sentido.

De certo, a reflexão é apenas o início de uma discussão muito maior, entretanto, uma manobra vestibular é necessária para o elucidar de conceitos em torno do projeto de Martin Heidegger em torno do ser. $\mathrm{O}$ recorte temático apresentado no presente artigo apenas reforça a posição da importância da literatura heideggeriana, uma vez a multiplicidade de leitores tão diversos, em situações tão plúrimas. Uma das possíveis temáticas na obra que ecoa em inúmeras vertentes e proporciona uma gama reflexiva única.

\section{REFERÊNCIAS}

DREYFUS, Hubert; WRATHALL, Mark. Martin Heidegger: an introduction to his tought, work and life. In: (org). A companion to Heidegger. Oxford: Blackwell, 2005.

FERREIRA, Acylene Maria Cabral. Culpa e angústia em Heidegger. Revista Cogito.

Salvador, vol.4, p.1-6, 2002.

FREDE, Dorothea. The question of being: Heidegger's project. In: GUIGNON, Charles B.(org). The Cambridge companion to Heidegger. Cambridge: Cambridge University Press, 1993.

GAOS, José. Introduccion a El Ser y El Tiempo de Martin Heidegger. Madrid: Fondo de Cultura Económica, 1986.

GUIGNON, Charles B. Introduction. In:

The Cambridge companion to Heidegger.

Cambridge: Cambridge University Press, 1993
HAAR, Michel. Heidegger e a essência do homem. Lisboa: Instituto Piaget, 1990.

HEIDEGGER, Martin. Ser y Tiempo. $2^{\text {a }}$ Edição. Santiago: Editorial Universitária, S.A., 1998.

Que é metafísica? São Paulo: Abril Cultural, 1989.

SEIBT, Cezar Luís. Poder-ser próprio: angústia e morte em Ser e Tempo de Heidegger. Revista Philosophica, Valparaíso, vol.35, p.181-197, semestre 1, 2009.

SHEEHAN, Thomas. Dasein. In: DREYFUS, Hubert; WRATHALL, Mark. (org). A Companion to Heidegger. Oxford: Blackwell, 2005,p.193-213.

STEIN, Ernildo. Introdução ao Pensamento de Martin Heidegger. Porto Alegre: EDIPUCRS, 2002.

Diferença e Metafísica: ensaios sobre a desconstrução. Porto Alegre: Edipucrs, 2000.

WERLE, Marco Aurélio. A angústia, o nada e a morte em Heidegger. Revista Trans/Form/Ação. São Paulo, vol.26, p.97-113, 2003.

\section{Bruno Gadelha Xavier}

Doutorando em Filosofia pela Universidade Federal do Rio de Janeiro (UFRJ). Doutorando em Educação pela Universidade Federal do Espírito Santo (UFES); Mestre e Doutorando em Direitos e Garantias Fundamentais pela Faculdade de Direito de Vitória (FDV); Mestre em Filosofia pela Universidade Federal do Espírito Santo (UFES); Pós-Graduado em Direito Processual Civil pela Faculdade de Direito de Vitória (FDV); Bacharel em Direito pela Faculdade de Direito de Vitória (FDV); Membro do Grupo de Pesquisa "Direito, Sociedade e Cultura" (FDV), do NEPEFIL - Núcleo de Estudos e Pesquisa em Educação e Filosofia (UFES), e do Grupo de Pesquisa Pensamento e Linguagem (UFES). Professor Universitário. 